\title{
Addictive profiles of Lebanese university students in terms of smoking, alcohol, and illegal drug use
}

\author{
Clarissa Chalhoub $^{1} \cdot$ Sahar Obeid $^{2,3,4} \cdot$ Rabih Hallit $^{1,5,6} \cdot$ Pascale Salameh $^{3,7,8} \cdot$ Souheil Hallit $^{1,3}$ (D)
}

Received: 3 May 2021 / Accepted: 2 June 2021 / Published online: 5 June 2021

(C) The Author(s), under exclusive licence to Springer-Verlag GmbH Germany, part of Springer Nature 2021

\begin{abstract}
The Lebanese economic crisis, financial crisis, and USD shortage were conducive to an increased drug addiction especially for students who feel that their future in Lebanon is not safe, as well as the psychological fragility of the Lebanese people, and the more permissive sociocultural context. Our study aimed to assess the addiction levels and profiles of university students in Lebanon, and thus to evaluate the rapid rising in dependence regarding smoking, alcohol, and illegal drug use during this crisis. This cross-sectional study was carried out between February and September 2020. A total of 467 participants (315 females, 152 males; Mage $=23.48 \pm 6.03$ ) were recruited through convenience sampling through several universities in Lebanon's governorates. Participants received the online link to the survey. Students were divided into three clusters as follows: cluster 1, which corresponds to students with moderate addictions; cluster 2, which corresponds to students with high addictions; and cluster 3, which corresponds to students with low addictions. When comparing cluster 1 to cluster 3 , the results of the multinomial regression showed that older age $(\mathrm{aOR}=1.08)$ and having a high monthly income compared to no income $(\mathrm{aOR}=2.78)$ were significantly associated with higher odds of being in cluster 1 compared to cluster 3 . When comparing cluster 2 to cluster 3 , the results of the multinomial regression showed that female gender $(\mathrm{aOR}=0.19)$ was significantly associated with lower odds of being in cluster 2 compared to cluster 3 , whereas having a dead $(\mathrm{aOR}=16.38)$ or divorced parent $(\mathrm{aOR}=6.54)$ and having a low $(\mathrm{aOR}=3.93)$ or intermediate income compared to zero income $(\mathrm{aOR}=4.71)$ were significantly associated with higher odds of being in cluster 2 compared to cluster 3 . The results of our study revealed a considerable prevalence of addiction to alcohol, illicit drugs, and specially to smoking, among Lebanese university students. These findings emphasize the need to implement firm policies and rules in an attempt to minimize the tendency of the young population to engage in such addictions.
\end{abstract}

Keywords Addiction $\cdot$ Smoking $\cdot$ Alcohol $\cdot$ Illicit drugs $\cdot$ University students $\cdot$ Lebanon

\section{Introduction}

Substance abuse was defined by the World Health Organization (WHO) as "persistent or sporadic excessive drug

Pascale Salameh and Souheil Hallit are the last co-authors.

Responsible Editor: Lotfi Aleya

Souheil Hallit

souheilhallit@hotmail.com

1 Faculty of Medicine and Medical Sciences, Holy Spirit University of Kaslik (USEK), Jounieh, Lebanon

2 Research and Psychology Departments, Psychiatric Hospital of the Cross, Jal ed Dib, Lebanon

3 INSPECT-LB: Institut National de Santé Publique, Épidémiologie Clinique et Toxicologie, Beirut, Lebanon use inconsistent with or unrelated to acceptable medical practice" (World Health Organization 1994). It is an overindulgence in any addictive substance. Addiction is now considered by the WHO as a dependence, which can exist in various
$4 \quad$ Faculty of Arts and Sciences, Holy Spirit University of Kaslik (USEK), Jounieh, Lebanon

5 Infectious Disease Department, Bellevue Medical Center, Mansourieh, Lebanon

6 Infectious Disease Department, Notre-Dame des Secours University Hospital, Byblos, Lebanon

7 University of Nicosia Medical School, Nicosia, Cyprus

8 Faculty of Pharmacy, Lebanese University, Hadat, Lebanon 
degrees of severity resulting in harmful academic and social consequences as well as causing health problems (World Health Organization 1994). An addictive behavior can affect human health, and seems to be on the rise especially among university students due to the availability of tobacco and other substances on campuses (Houri and Hammoud 2005). Addictive substances include illicit drugs (cocaine, heroin, ecstasy, marijuana, hallucinogens, etc.) that are highly addictive and licit drugs (prescription drugs), in addition to alcohol and cigarette/waterpipe smoking.

While students are excited to kick off this new phase of life, university is considered a fresh start for every student, full of new experiences. This is a phase of transition from restricted parents' life to a self-directed one (Osman et al. 2016). Previous findings revealed that university students are more prone to drug use and substance addiction related to four components: problems and coping, sensation seeking, social environment, and disposition (Cirakoglu and Isin 2005). Students experience more freedom, integrate into new friends' groups, expose to different academic pressures, and may share new living style (Osman et al. 2016).

Tobacco consumption causes approximately 6 million deaths per year and is expected, in the near future, to result in more than 8 million deaths annually especially in developing countries (World Health Organization 2008). Smoking dependence has been reported worldwide with high predominance among university students (Tamim et al. 2003). The smoking epidemic in Lebanon is not only attributed to cigarette smoking that remains widespread but also for the new waterpipe trend. The prevalence of waterpipe smoking in Lebanon is $43 \%$ while that of cigarette is $29 \%$ in university students, where $60 \%$ of adults smoke cigarettes/waterpipe or have tried it at least once (Tamim et al. 2003; World Health Organization 2008). The regional report economics of tobacco for the Middle East and North Africa region (MENA) reported that Lebanon has a high prevalence of 53\% of youth smokers in university population compared to other Arab countries such as Oman with 7\%, 6.8\% in Yemen as reported by the Global Youth Tobacco Survey (GYTS), and $19.8 \%$ in Palestine, studied by the Palestinian Central Bureau of Statistics (PCBS) (Nasser and Zhang 2019).

Alcohol consumption is increasing worldwide and is considered the substance of choice on campuses (Young and de Klerk 2008). Its prevalence is mostly dependent from religion where Muslims are forbidden by their religion from drinking alcohol with a prevalence of $39 \%$ compared to $82 \%$ of Christian students (Houri and Hammoud 2005). University students are at a stage where they can experience more freedom in their behaviors such as alcohol consumption (Chu et al. 2016). Studies showed that $90 \%$ of students have consumed alcohol at least one time while $40 \%$ are binge drinker (Lukács et al. 2013), and many factors can affect student's potential for increased alcohol consumption like higher education degree, male gender, stress, family dissociation, and high income (Houri and Hammoud 2005; Young and de Klerk 2008).

Non-illicit drugs, either prescription or non-prescription drugs, are abused at a continually increasing rate among university students (Kerbage and Haddad 2014; Manubay et al. 2011). Approximately, 59\% of UK university students abused, in general, illicit drugs with $20 \%$ use on a regular basis reporting male predominance of $60 \%$ vs $55 \%$ of women. Moreover, $13 \%$ began abusing drugs after joining the university, and the most common reason was the pleasure. LSD and amphetamines were the most used after cannabis with a $20 \%$ rate (Webb et al. 1996). Smokers and alcohol consumers show a correlation with drug addicts especially males (World Health Organization 1994). In Lebanon, opioids appear to be the most abused type of prescription drug. After opioids, $13.1 \%$ of university students misuse tranquilizers (Ghandour et al. 2008).

The United Nation panel warned that prescription drug such as tranquilizers and sedatives will soon overpass illicit drug use (Kuehn 2007). Despite that, cannabis is the only abused illegal drug more than prescribed drugs with a rate of $8.8 \%$ of university students and $8 \%$ abusing hashish/ marijuana (Ghandour et al. 2008; Kuehn 2007). The high availability of prescription drugs enhanced their non-medical use, and it's proven that the toxicity from legal drugs is much dangerous than illegal ones and has more health repercussions (McHugh et al. 2015).

Cluster analysis is used to detect and differentiate subgroups of individuals with similar characteristics, clinical signs, and symptoms. Thus, its use may be helpful to better capture the behavioral patterns of people with different addictions (Hamid et al. 2010). The 3 groups were divided from the largest one to the smallest, respectively, with $43 \%$ for the group with highest risk, $36 \%$, and $21 \%$ of participants (Schonnesson et al. 2008).

There is a global burden of drug abuse in correlation with smoking and alcohol consumers. Cultural tolerance and social acceptance for smoking in Turkey make it easier for students to increase the addiction risk (Karatay and Bas 2019). In European countries, opposite to Lebanon, illicit drugs are considered legal, which increase the rate of its freely consumption. The Lebanese economic crisis and COVID-19 pandemic were conducive to an increased drug addiction especially for students with unguaranteed future in Lebanon, as well as psychological fragility of the Lebanese people (El Othman et al. 2021), and the more permissive sociocultural context. This research seemed essential to be conducted in the current economic, political, and health crisis that the country is facing and that is taking its toll especially on the young population. Our study aimed to assess the addiction levels and profiles of university students in Lebanon, and thus to evaluate the rapid 
rising in dependence regarding smoking, alcohol, and illegal drug use during this crisis.

\section{Methods}

\section{Study design and participants}

This cross-sectional study was carried out between February and September 2020. A total of 467 participants (315 females, 152 males; Mage $=23.48 \pm 6.03$ ) was recruited through convenience sampling through several universities in Lebanon's governorates. Participants received the online link to the survey. https://docs.google.com/forms/d/e / 1 F A I p Q L S e y b 2 o O Q B v p L G D 7 h H 1 QtxzYG57YL894YPEPcY23oxYt3oPXsw/viewform?vc= $0 \& \mathrm{c}=0 \& \mathrm{~W}=1$.Involved people were encouraged to visit a website that would guide them to the consent form, information form (purpose of the current study, anonymity, voluntariness of consent to research), and questionnaire. All participants responded willingly to the survey. There were no fees for participating in the study. All university students over the age of 18 were eligible to participate. Those who refused to complete the survey were excluded.

\section{Minimal sample size calculation}

Based on a 53.3\% frequency of alcohol use among university students (Kerbage and Haddad 2014), and a 5\% risk of error, the Epi-info software calculate a minimal sample size of 382 .

\section{Questionnaire}

The survey was in English, one of the two educational languages in Lebanon. The questionnaire consisted of two parts. Part one included the sociodemographic characteristics of the participants (age, gender, parents' status (living together or divorced), marital status, monthly income, governorate, and specialty). Part two consisted of scales/measures used in this study:

Fagerstrom Test for Nicotine Dependence (FTND) A common tool for measuring the severity of physical addiction to nicotine is the Fagerstrom test for nicotine dependence (Heatherton et al. 1991). It is validated in Lebanon (Salameh et al. 2014) and comprises six questions that measure the level of intake of tobacco, the compulsion to consume, and dependency. The higher the score, the more the severity of nicotine dependence (Cronbach's alpha in this study=0.741).

Lebanese Waterpipe Dependence Scale (LWDS) It was the first test to characterize the severity of waterpipe dependence in Lebanon based on a threshold score of 10 with 11 questions about waterpipe smoking answered according to a Likert scale (Cronbach's alpha in this study=0.893) (Salameh et al. 2008).

The Alcohol Use Disorders Identification Test (AUDIT) It is a 10 -items scale used to evaluate unhealthy alcohol use, drinking patterns, and health-related alcohol use issues (World Health Organization 2001). Questions illustrate different alcohol drinking way and assess the number of drinks. A harmful and hazardous alcohol use is considered with a score more than 8 (Cronbach's alpha in this study $=0.822$ ).

Non-alcohol psychoactive substance use disorder (MINI) The MINI was designed as a brief study for the major axis I psychiatric disorders in DSM-5 and ICD-10. Questions evaluate the use of 8 illicit drugs in the last 12 months, according to a yes/no type of answer (Lecrubier et al. 1997). This scale is validated in Arabic (Kadri et al. 2005) (Cronbach's alpha in this study $=0.622$ ).

\section{Statistical analysis}

Statistical analyses were carried out using the Statistical Package for Social Sciences 25.0 (SPSS, Chicago, IL, USA). A cluster analysis, using the K-mean method, was conducted in order to classify participants according to their patterns (into three clusters). All scores were standardized before conducting the cluster analysis. The Chi-square test was used to check for a difference in terms of categorical variables between clusters, whereas ANOVA test was used to compare three or more means. A multinomial regression was conducted next, taking the clusters as the dependent variable (the cluster of students with low addiction was taken as the reference group). All studied variables that showed a $p<0.2$ in the bivariate analysis were taken as independent variables in the final model. Cronbach's alpha values were recorded for reliability analysis of all scales and subscales. Significance was set at $\mathrm{p}<0.05$.

\section{Results}

\section{Sociodemographic characteristics of the participants}

The mean age of the participants was $23.48 \pm 6.03$ years, with $67.5 \%$ females. The majority of the participants were single and had married parents. The full description of the participants' characteristics is summarized in Table 1.

\section{Cluster analysis}

Students were divided into three clusters as follows: cluster 1, which corresponds to students with moderate addictions (moderate cigarette dependence, problematic alcohol use, 
Table 1 Sociodemographic characteristics of the students ( $N=467)$

\begin{tabular}{ll}
\hline Variable & $\mathrm{N}(\%)$ \\
\hline Gender & \\
Male & $152(32.5 \%)$ \\
Female & $315(67.5 \%)$ \\
Monthly income & \\
No income & $262(56.1 \%)$ \\
Low (<1000 USD) & $113(24.2 \%)$ \\
Intermediate (1000-2000 USD) & $56(12.0 \%)$ \\
High (>2000 USD) & $36 .(7.7 \%)$ \\
Governorate & \\
Beirut & $110(23.4 \%)$ \\
Mount Lebanon & $231(49.5 \%)$ \\
North Lebanon & $67(14.4 \%)$ \\
South Lebanon & $33(7.1 \%)$ \\
Bekaa & $26(5.6 \%)$ \\
Parental situation & \\
Married & $422(90.4 \%)$ \\
Divorced & $29(6.2 \%)$ \\
Orphan & $16(3.4 \%)$ \\
Marital status & \\
Single & $428(91.6 \%)$ \\
Married & $39 .(8.4 \%)$ \\
Age (in years) & Mean \pm SD \\
\hline & $23.48 \pm 6.03$ \\
\hline
\end{tabular}

and use of illegal drugs/substances and high waterpipe dependence); cluster 2, which corresponds to students with high addictions (high cigarette dependence, problematic alcohol use, and use of illegal drugs/substances and moderate waterpipe dependence); and cluster 3, which corresponds to students with low addictions (low cigarette dependence, low waterpipe dependence, low problematic alcohol use, and lower use of illegal drugs/substances) (Table 2).

\section{Bivariate analysis}

A significantly higher percentage of female participants, with no income and whose parents were married, had lower addictions (belonged to cluster 3). Moreover, a significantly lower mean age was found in students belonging to cluster 3 compared to the other 2 clusters (Table 3 ).

When comparing cluster 1 vs cluster 2 , the results showed that a significantly higher percentage of females $(61.5 \%$ vs $32.6 \%$ ), of those who had a low income $(40.0 \%$ vs $25.6 \%$ ), and married ( $89.2 \%$ vs $67.4 \%$ ) belonged to cluster 1 compared to cluster 2 .

Post hoc analysis: age (cluster 1 vs cluster $3 \mathrm{p}=0.002$ ); gender (cluster 1 vs cluster $2 \mathrm{p}=0.003$ ); monthly income
Table 2 Cluster analysis: profiles of the students in terms of addictions

\begin{tabular}{|c|c|c|c|}
\hline Variable & $\begin{array}{l}\text { Cluster } 1 \\
(\mathrm{~N}=65 ; \\
13.92 \%)\end{array}$ & $\begin{array}{l}\text { Cluster } 2 \\
(\mathrm{~N}=43 ; \\
9.21 \%)\end{array}$ & $\begin{array}{l}\text { Cluster } 3 \\
(\mathrm{~N}=359 ; \\
76.87 \%)\end{array}$ \\
\hline Cigarette dependence & -0.10 & 2.39 & -0.27 \\
\hline $\begin{array}{l}\text { Waterpipe } \\
\text { dependence }\end{array}$ & 2.02 & 0.48 & -0.42 \\
\hline $\begin{array}{l}\text { Problematic alcohol } \\
\text { use }\end{array}$ & 0.26 & 1.68 & -0.25 \\
\hline Illegal drug use & 0.13 & 1.80 & -0.24 \\
\hline
\end{tabular}

(cluster 1 vs cluster $2 \mathrm{p}=0.045$ ); parental situation (cluster 1 vs cluster $2 \mathrm{p}=0.02$ )

\section{Multivariable analysis}

When comparing cluster 1 to cluster 3 , the results of the multinomial regression showed that older age $(\mathrm{aOR}=1.08)$ and having a high monthly income compared to no income $(\mathrm{aOR}=2.78)$ were significantly associated with higher odds of being in cluster 1 compared to cluster 3 (Table 4, Model 1).

When comparing cluster 2 to cluster 3 , the results of the multinomial regression showed that female gender $(\mathrm{aOR}=0.19)$ was significantly associated with lower odds of being in cluster 2 compared to cluster 3 , whereas having a dead $(\mathrm{aOR}=16.38)$ or divorced parent $(\mathrm{aOR}=6.54)$ and having a low $(\mathrm{aOR}=3.93)$ or intermediate income compared to no income $(\mathrm{aOR}=4.71)$ were significantly associated with higher odds of being in cluster 2 compared to cluster 3 (Table 4, Model 2).

The results of the forward logistic regression, conducted on participants belonging to clusters 1 and 2 only, showed that females had significantly higher odds of belonging to cluster 1 vs cluster $2(\mathrm{aOR}=3.34 ; \mathrm{p}=0.01 ; 95 \%$ CI 1.34 8.34), whereas having orphan $(\mathrm{aOR}=0.17 ; \mathrm{p}=0.033 ; 95 \%$ CI $0.03-0.87)$ or divorced $(\mathrm{aOR}=0.20 ; \mathrm{p}=0.035 ; 95 \% \mathrm{CI}$ 0.05-0.89) parents compared to married ones had lower odds of belonging to cluster 1 compared to cluster 2 (data not shown in Table 4).

\section{Discussion}

Lebanon is a country where self-medicating is very common, and where most drugs are available without the need for a physician's prescription. This reality could be susceptible to play a part in facilitating substance abuse and misuse with the current situation in Lebanon. To the best of our knowledge, there has not been any recent study evaluating the prevalence of addiction to both licit (smoking, alcohol) and illicit substances in the young 
Table 3 Bivariate analysis of factors associated with the clusters

\begin{tabular}{|c|c|c|c|c|}
\hline Variable & Cluster 1 & Cluster 2 & Cluster 3 & $P$ \\
\hline Gender & & & & $<0.001$ \\
\hline Male & $25(38.5 \%)$ & $29(67.4 \%)$ & $98(27.3 \%)$ & \\
\hline Female & $40(61.5 \%)$ & $14(32.6 \%)$ & $261(72.7 \%)$ & \\
\hline Monthly income & & & & $<0.001$ \\
\hline No income & $23(35.4 \%)$ & $11(25.6 \%)$ & $228(63.5 \%)$ & \\
\hline Low (<1000 USD) & $26(40.0 \%)$ & $11(25.6 \%)$ & $76(21.2 \%)$ & \\
\hline Intermediate (1000-2000 USD) & $7(10.8 \%)$ & $13(30.2 \%)$ & $36(10.0 \%)$ & \\
\hline High (>2000 USD) & $9(13.8 \%)$ & $8(18.6 \%)$ & $19(5.3 \%)$ & \\
\hline Governorate & & & & 0.901 \\
\hline Beirut & $15(23.1 \%)$ & $9(20.9 \%)$ & $85(23.7 \%)$ & \\
\hline Mount Lebanon & $35(53.8 \%)$ & $26(60.5 \%)$ & $170(47.5 \%)$ & \\
\hline North Lebanon & $7(10.8 \%)$ & $4(9.3 \%)$ & $56(15.6 \%)$ & \\
\hline South Lebanon & $4(6.2 \%)$ & $2(4.7 \%)$ & $27(7.5 \%)$ & \\
\hline Bekaa & $4(6.2 \%)$ & $2(4.7 \%)$ & $20(5.6 \%)$ & \\
\hline Parental situation & & & & $<0.001$ \\
\hline Married & $58(89.2 \%)$ & $29(67.4 \%)$ & $335(93.3 \%)$ & \\
\hline Divorced & $4(6.2 \%)$ & $7(16.3 \%)$ & $18(5.0 \%)$ & \\
\hline Orphan & $3(4.6 \%)$ & $7(16.3 \%)$ & $6(1.7 \%)$ & \\
\hline Marital status & & & & 0.09 \\
\hline Single & $58(89.2 \%)$ & $36(83.7 \%)$ & $334(93.0 \%)$ & \\
\hline Married & $7(10.8 \%)$ & $7(16.3 \%)$ & $25(7.0 \%)$ & \\
\hline Age & $25.44 \pm 6.01$ & $27.12 \pm 8.82$ & $22.68 \pm 5.36$ & $<0.001$ \\
\hline
\end{tabular}

population, particularly during the current economic and political crisis that the Lebanese population is encountering, adding up to the pandemic of COVID-19. Our sample was divided into three clusters depending on the level of addiction of the participants. Based on the data in our study, the majority of university students appeared to have a low addiction profile (76.87\%), and only $9.21 \%$ were found to have a high addiction to licit or illicit substances; these findings support those found in previous studies which assessed the prevalence of substance use among university students (Mekonen et al. 2017a).

According to our findings, the addiction of participants in the different clusters, regardless of their level of addiction, appears to be mostly related to smoking (cigarette/ waterpipe) and to a lower degree to alcohol and illicit drug use. The results of our study among Lebanese university students do not align with the international research in which alcohol appears to be the most consumed and prevalent addictive substance among university students (Ruisoto et al. 2016). According to the Society for the Study of Addiction (SSA) in 2017, alcohol use and tobacco smoking in the adult population (aged $\geq 15$ years) are far more prevalent than illicit substance use globally, and are responsible for the majority of health burden from substance use (Peacock et al. 2018).

\section{Factors associated with the clusters}

\section{Age}

According to our study, there is a negative association between lower age and levels of addiction of university students. These findings come in line with the international literature in which age appears to be a predictive factor of substance use, as illustrated in a previous paper regarding both alcohol and tobacco use (Mostardinha and Pereira 2019).

Furthermore, in a study conducted among university students in Northern Ireland, Wales, and England, in 2014 (El Ansari et al. 2014), regular and occasional illicit drug use appeared to be the most prevalent among the age group of middle-aged students (21-29 years old) as compared to younger students (18-21 years). But students aged $>29$ years were not more likely to use illicit drug/s when compared with younger students ( $<21$ years). Additionally, the National Survey on Drug Use and Health (NSDUH) reported similar results in their annual survey in 2012 (Kerr-Correa et al. 2007; Substance Abuse and Mental Health Services Administration 2012), which stated that illicit drug use was the highest among young adults of the age group: 18 to 20 years old, and then 21 to 25 years old (19.7\%); thereafter, the rate generally declined with age. Comparable findings were 
Table 4 Multivariable analysis: multinomial regression taking the clusters as the dependent variable

\begin{tabular}{|c|c|c|c|}
\hline Age & 0.027 & 1.08 & $1.01-1.15$ \\
\hline Gender (females vs males*) & 0.143 & 0.65 & $0.37-1.16$ \\
\hline Marital status (married vs single*) & 0.114 & 0.33 & $0.09-1.31$ \\
\hline \multicolumn{4}{|l|}{ Parental status } \\
\hline Orphan vs married* & 0.174 & 2.86 & $0.63-13.03$ \\
\hline Divorced vs married* & 0.679 & 1.28 & $0.40-4.13$ \\
\hline \multicolumn{4}{|l|}{ Monthly income } \\
\hline Low $(<1000$ USD) vs no income* & 0.072 & 2.69 & $0.91-7.93$ \\
\hline Intermediate (1000-2000 USD) vs no income* & 0.643 & 1.27 & $0.46-3.49$ \\
\hline High (>2000 USD) vs no income* & 0.002 & 2.78 & $1.46-5.33$ \\
\hline \multicolumn{4}{|l|}{ Model 2: cluster 2 vs cluster $3^{*}$} \\
\hline Age & 0.236 & 1.05 & $0.97-1.14$ \\
\hline Gender (females vs males*) & $<0.001$ & 0.19 & $0.09-0.41$ \\
\hline Marital status (married vs single*) & 0.443 & 0.57 & $0.14-2.39$ \\
\hline \multicolumn{4}{|l|}{ Parental status } \\
\hline Orphan vs married* & $<0.001$ & 16.38 & $4.10-65.38$ \\
\hline Divorced vs married* & 0.001 & 6.54 & $2.15-19.91$ \\
\hline \multicolumn{4}{|l|}{ Monthly income } \\
\hline Low $(<1000$ USD) vs no income* & 0.047 & 3.93 & $1.02-15.17$ \\
\hline Intermediate (1000-2000 USD) vs no income* & 0.004 & 4.71 & $1.62-13.69$ \\
\hline High (>2000 USD) vs no income* & 0.144 & 2.06 & $0.78-5.45$ \\
\hline
\end{tabular}

*Reference group; $C I$ confidence interval also obtained and applicable in regard to alcohol use and tobacco smoking (Substance Abuse and Mental Health Services Administration 2012). This does not come as a surprise since this age range is marked by a transition for the young university students, (i.e., presence of a new environment, family and academic pressure, decisions regarding their personal future, stress...) in which students find themselves at higher risk for substance and drug use, which is translated by the initiation of substance use that is found globally among university students (El Ansari et al. 2014; Locke et al. 2015; Maier et al. 2013).

\section{Gender}

Our study shows a negative association between female gender and the level of addiction profile. Female gender appears to be associated with lower addiction compared to males, which is consistent with the international literature (Degenhardt et al. 2008; Goreishi and Shajari 2013; Mostardinha and Pereira 2019); in a large international survey describing data from 17 countries participating in the World Health Organization's (WHO) World Mental Health (WMH) Survey Initiative in 2008 , in which participants were divided into sub-groups depending on their age, women across the different countries appeared to be less likely than men, in any given year of life, to initiate drug use, while men were more likely than females to have used all drug types (alcohol, cocaine, tobacco, and cannabis) (Degenhardt et al. 2008).

The discrepancy between addiction profiles between men and women can be explained by the fact that substance use disorders are considered to be a form of externalizing behaviors that are generally more common among men than women, women being more prone internalizing problems, such as depression or anxiety (Bierhoff et al. 2019; Smith et al. 2018). Indeed, many previous studies attempted to assess how internalizing and externalizing psychopathology were correlated with alcohol dependence in men and women of various ages (Bierhoff et al. 2019; Eaton et al. 2012; Tavolacci et al. 2013). Moreover, the association between impulsivity traits and substance use in the psychopathology of addictions, which was not assessed in our study, could in part explain why male students use drugs more than women, as impulsivity disorders appear to be more prevalent among men according to several studies that were conducted in Europe and the USA (Bravo et al. 2018; Delgado-Lobete et al. 2020; Mitchell and Potenza 2014).

In Lebanon in particular, the cultural background which is more permissive of the idea of smoking and alcohol use in men than women may have played a role in protecting women from developing smoking alcohol problems (Degenhardt et al. 2008). Smoking and drinking are usually discouraged in women, for being considered incompatible with traditionally 
feminine traits detained by society, each society having a different acceptance level for female smoking and drinking (Cui et al. 2018; Kerr-Correa et al. 2007). In contrast with international studies conducted in Europe and Saudi Arabia, waterpipe use appeared to be more prevalent in female Lebanese university students than in males. These findings can be explained by the fact that waterpipe has a "softer" and more acceptable image among the Lebanese population when compared to cigarette smoking; moreover, it is falsely believed to be less harmful and safer than cigarette smoking by the Lebanese population, which makes it more appealing and more popular among females and youth (Albisser et al. 2013; Farah et al. 2020; Hallit et al. 2020; Mahfouz et al. 2014). Furthermore, a study realized in 2007 evaluating the patterns of alcohol use between genders shed light on the fact that women affected by the problematic use of alcohol were more likely to suffer from social discrimination and family neglect than men (Kerr-Correa et al. 2007). Not to forget the peer influence contribution to young adult substance use, which might be more prevalent between males in Lebanon, and that is susceptible to play an important part in introducing young university students to smoking and substance use (Delgado-Lobete et al. 2020; Mostardinha and Pereira 2019).

\section{Family status}

The findings of this study point out to the presence of an association between parental status and higher addiction. Participants with a deceased or divorced parent appear to be associated with a higher addiction profile than those with married parents. In a previous study, orphans, victims of parenteral loss, and children with divorced parents were more likely to be subjects to financial burden and psychosocial adjustment difficulties, therefore contributing to higher addiction and substance use problems (Huurre et al. 2010).

These results correlate with findings from previous international studies as adolescents living in non-intact families reported daily smoking, binge drinking, and regular cannabis use much more frequently than those living in intact families (Kerr-Correa et al. 2007; Redonnet et al. 2012). This can be explained by the increased level of stress and adversity that can be found in disrupted families compared to intact ones and that is more likely to drive the young adolescents into smoking and consumption behaviors as part of potential coping mechanisms. In addition, university students with a deceased parent are more likely to face less supervision and less authority which may permit more permissive rules and less apprehension of the parenteral figure. Young students might find less support in their disrupted or non-intact families and might engage in such behaviors as their only way out and a solution to their problems (Barrett and Turner 2006).

\section{Economic status}

According to our research, economic status of university students appears to be a possible contributing factor in increasing addiction. Both low and moderate SES appear to have a positive association with higher addiction profiles, whereas high SES was associated with moderate addictive profile. These results reflect those found in previous studies, concerning the association between substance use and the socioeconomic context of the university students, since both affluent and poor participants are involved in higher addictions.

According to a study by El Ansari W. et al. conducted in 2018 (El Ansari et al. 2014), affluent students of high-income groups (i.e., parents with highest income, postgraduate training) are at greater risk for alcohol and marijuana use during the transition to adulthood (El Ansari et al. 2014; Luthar and Latendresse 2005). The reason of these findings might be attributable to an increased and easier access to money in high SES university students, not to mention higher performance pressures, and less adult oversight which might explain why students of parents with higher incomes are more likely to engage in more negative health behaviors (Patrick et al. 2012). Parents of high SES might adopt more permissive attitudes, and less supervision due to their demanding careers.

However, findings concerning the association of different types of substance addiction and the socio-economic context of the students appear sometimes contradictory in the literature, smoking being associated with lower SES, and drinking with higher SES (Mostardinha and Pereira 2019; Patrick et al. 2012). University students with low-income parents are likely to grow up in environments where smoking is prevalent, and in they have role models such as their parents, siblings, and neighborhood who smoke or are involved in other forms of substance use (Redonnet et al. 2012). So, further research might be needed in order to better assess the association between the economic status and higher addiction profiles. According to the World Drug Report (2020) of the UNODC (United Nations Office on Drugs and Crime), this is more important than ever, as illicit drug challenges become increasingly complex, and the COVID-19 crisis and economic downturn threaten to worsen their impacts, on the poor, marginalized, and vulnerable most of all (United Nations Office on Drugs and Crime).

\section{Clinical implications}

Given the economic and political crisis that are superimposing on the already alarming pandemic in Lebanon and the unemployment situation of youth, university students appear to be exceedingly affected and helpless facing this current situation. All of these factors are susceptible to have a considerable impact and play a considerable part in guiding students toward smoking, alcohol, drugs, and other consumption behaviors. 
Additionally, the health care system allowing the young adolescents access to many over-the-counter drugs without the need to a prescription from health care professionals and pharmacies may facilitate even more such behaviors and abuse. Drugs are the escape for the youth who might perceive it as the only remedy for their present situation.

Conducting our study seemed essential in the absence of any new research about the prevalence of addiction in university students in the last 2 decades, and especially in the light of the current circumstances as it may help, at first, shed light on the increasing illicit drug use in university students, some of which appeared to have a high prevalence of addiction (Degenhardt et al. 2019; Karjalainen et al. 2017; Talih et al. 2018). Second in education regarding random substance use and its various dangers on both their health and future (El Ansari et al. 2018), addiction appears to be a major source of loss of productivity (Mekonen et al. 2017b) and source of indirect costs for the society. Finally, attempting to obtain serious penalties for prescription drug misuse like other international countries, as well as implementing firm policies regarding substance use and drug availability are warranted in Lebanon.

\section{Limitations}

As all studies, our cross-sectional study has limitations; it does not allow acquiring causal relationships. Due to the COVID19 pandemic, a self-administered questionnaire was distributed via an online form, which can be a source of potential bias considering the adherence that may be overestimated, where also there's risk of misunderstanding questions and recall deficiency. The refusal rate may cause a selection bias. In addition, the frequencies of cigarette/waterpipe smoking and alcohol consumption are subjective variables, and can lead to information bias. Moreover, some participants where older than the targeted population and due to some religious beliefs, the AUDIT test was not well evaluated since the correlation between alcohol and other variables is not present. Furthermore, the total sample size is sufficient, withdrawn from six governorates in Lebanon with some limitations while working with private institutions. Some possible confounding factors could have played a part in affecting the results of our study, which were not assessed in our research, such as (1) personal life stressors and psychiatric disorders (anxiety, depression) (Esmaeelzadeh et al. 2018), (2) religious involvement, which was found to be a strong protective factor against substance use (tobacco, alcohol and illicit drugs) in various studies, possibly due to the different values that comes with the religion, better self-control, and more accessible social support (El Ansari et al. 2014; Gomes et al. 2013). O (3) socio-demographic factors such as having parents/friends who drink / smoke, and living or not in university dorms (alone or with other students), since the change of environment for some of the students that are living apart from their parents for the first time or with friends, could cause a possible break in some habits and the adoption of new lifestyles (Delgado-Lobete et al. 2020; Ramis et al. 2012). However, the acceptable sample size covering all Lebanese regions and the university students that were good candidates to be chosen for such a study consents a close approach of the findings to the general population since no such studies have already directed in Lebanon, even though it does not allow the generalization of the results to the entire Lebanese population.

\section{Conclusion}

The results of our study revealed a considerable prevalence of addiction to alcohol, illicit drugs, and specially to smoking, among Lebanese university students. Each of the gender, socio-economic, and familial status of the participants was predictive of their level of addiction. Indeed, female gender, intact family, and high socio-economic status of the students predicted lower addiction among the subjects. These findings emphasize the need to implement firm policies and rules in an attempt to minimize the tendency of the young population to engage in such addictions. Future research is needed in order to evaluate the prevalence of addiction of university students to each drug specifically, both licit (opioids, tranquilizers...) and illicit ones (cannabis, marijuana...), which could assist the government in better targeting the vulnerable, and at risk populations for addiction, thus preventing the increase of addiction among university students in spite of the considerable risk factors associated with this phase of their life along with the current economic and health-related situation in Lebanon.

Acknowledgements The authors would like to thank all the participants.

Availability of data and materials The authors do not have the right to share any data information as per their institutions policies.

Author contribution SH and PS designed the study; CC drafted the manuscript; SH and PS carried out the analysis and interpreted the results; $\mathrm{RH}$, $\mathrm{SO}$, and HS assisted in drafting and reviewing the manuscript; all authors reviewed the final manuscript and gave their consent.

\section{Declarations}

Ethics approval and consent to participate The Psychiatric Hospital of the Cross Ethics and Research Committee approved this study protocol (HPC-047-2020). Submitting the form online was considered equivalent to obtaining a written informed consent.

Consent to publish Not applicable

Competing interests The authors declare no competing interests. 


\section{References}

Albisser S, Schmidlin J, Schindler C, Tamm M, Stolz D (2013) Water pipe smoking and its association with cigarette and cannabis use in young adults in Switzerland. Respiration 86:210-215

Barrett AE, Turner RJ (2006) Family structure and substance use problems in adolescence and early adulthood: examining explanations for the relationship. Addiction 101:109-120

Bierhoff J, Haardorfer R, Windle M, Berg CJ (2019) Psychological risk factors for alcohol, cannabis, and various tobacco use among young adults: a longitudinal analysis. Subst Use Misuse 54:1365-1375

Bravo AJ, Pearson MR, Pilatti A, Read JP, Mezquita L, Ibanez MI, Ortet G (2018) Impulsivity-related traits, college alcohol beliefs, and alcohol outcomes: examination of a prospective multiple mediation model among college students in Spain, Argentina, and USA. Addict Behav 81:125-133

Chu JJ, Jahn HJ, Khan MH, Kraemer A (2016) Alcohol consumption among university students: a Sino-German comparison demonstrates a much lower consumption of alcohol in Chinese students. J Health Popul Nutr 35:1-11

Cirakoglu OC, Isin G (2005) Perception of drug addiction among Turkish university students: causes, cures, and attitudes. Addict Behav 30:1-

Cui Y, Zhu Q, Lou C, Gao E, Cheng Y, Zabin LS, Emerson MR (2018) Gender differences in cigarette smoking and alcohol drinking among adolescents and young adults in Hanoi, Shanghai, and Taipei. J Int Med Res 46:5257-5268

Degenhardt L, Chiu W-T, Sampson N, Kessler RC, Anthony JC, Angermeyer M, Bruffaerts R, De Girolamo G, Gureje O, Huang Y (2008) Toward a global view of alcohol, tobacco, cannabis, and cocaine use: findings from the WHO World Mental Health Surveys. PLoS Med 5:e141

Degenhardt L, Bharat C, Glantz MD, Sampson NA, Scott K, Lim CC, Aguilar-Gaxiola S, Al-Hamzawi A, Alonso J, Andrade LH (2019) The epidemiology of drug use disorders cross-nationally: findings from the WHO's World Mental Health Surveys. Int J Drug Policy $71: 103-112$

Delgado-Lobete L, Montes-Montes R, Vila-Paz A, Cruz-Valino JM, Gandara-Gafo B, Talavera-Valverde MA, Santos-Del-Riego S (2020): Individual and environmental factors associated with tobacco smoking, alcohol abuse and illegal drug consumption in university students: a mediating analysis. Int J Environ Res Public Health 17

Eaton NR, Keyes KM, Krueger RF, Balsis S, Skodol AE, Markon KE, Grant BF, Hasin DS (2012) An invariant dimensional liability model of gender differences in mental disorder prevalence: evidence from a national sample. J Abnorm Psychol 121:282-288

El Ansari W, Vallentin-Holbech L, Stock C (2014) Predictors of illicit drug/s use among university students in Northern Ireland, Wales and England. Global J Health Sci 7:18-29

El Ansari W, Ssewanyana D, Stock C (2018) Behavioral health risk profiles of undergraduate university students in England, Wales, and Northern Ireland: a cluster analysis. Front Public Health 6:120

El Othman R, Touma E, El Othman R, Haddad C, Hallit R, Obeid S, Salameh P, Hallit S (2021) COVID-19 pandemic and mental health in Lebanon: a cross-sectional study. Int J Psychiatry Clin Pract:1-12

Esmaeelzadeh S, Moraros J, Thorpe L, Bird Y (2018) The association between depression, anxiety and substance use among Canadian post-secondary students. Neuropsychiatr Dis Treat 14:3241-3251

Farah R, Haddad C, Sacre H, Hallit S, Salameh P (2020) Knowledge and attitude toward waterpipe smoking: scale validation and correlates in the Lebanese adult population. Environ Sci Pollut Res Int 27: $31250-31258$

Ghandour L, Karam E, Maalouf W, Salamoun M (2008): A rapid situation assessment of substance use and misuse in Lebanon: a step towards a national drug demand reduction plan. Available from: https:/www.drugabuse.gov/international/abstracts/rapid-situationassessment-substance-use-misuse-in-lebanon-step-towardsnational-drug-demand.

Gomes FC, de Andrade AG, Izbicki R, Moreira Almeida A, Oliveira LG (2013) Religion as a protective factor against drug use among Brazilian university students: a national survey. Braz J Psychiatry 35:29-37

Goreishi A, Shajari Z (2013) Substance abuse among students of Zanjan's Universities (Iran): a knot of today's society. Addiction \& health 5:66

Hallit S, Haddad C, Bou Malhab S, Khabbaz LR, Salameh P (2020) Construction and validation of the water pipe harm perception scale (WHPS-6) among the Lebanese population. Environ Sci Pollut Res Int 27:3440-3448

Hamid JS, Meaney C, Crowcroft NS, Granerod J, Beyene J, Group UKEoES (2010) Cluster analysis for identifying sub-groups and selecting potential discriminatory variables in human encephalitis. BMC Infect Dis 10:364

Heatherton TF, Kozlowski LT, Frecker RC, Fagerstrom KO (1991) The Fagerström test for nicotine dependence: a revision of the Fagerstrom Tolerance Questionnaire. Br J Addict 86:1119-1127

Houri A, Hammoud M (2005) Addictive behaviors amongst university students: contributing factors, student's perception and addiction rates. J Soc Sci 1:105-113

Huurre T, Lintonen T, Kaprio J, Pelkonen M, Marttunen M, Aro H (2010) Adolescent risk factors for excessive alcohol use at age 32 years. A 16-year prospective follow-up study. Soc Psychiatry Psychiatr Epidemiol 45:125-134

Kadri N, Agoub M, El Gnaoui S, Alami KM, Hergueta T, Moussaoui D (2005) Moroccan colloquial Arabic version of the Mini International Neuropsychiatric Interview (MINI): qualitative and quantitative validation. European psychiatry 20:193-195

Karatay G, Bas NG (2019) Factors affecting substance use and selfefficacy status of students in eastern Turkey. Cien Saude Colet 24: $1317-1326$

Karjalainen K, Lintonen T, Hakkarainen P (2017) Illicit drug use is increasing among non-medical users of prescription drugs-results from population-based surveys 2002-2014. Drug Alcohol Depend 178:430-434

Kerbage H, Haddad R (2014): Lebanon: drug situation and policy. Available from: https://rm.coe.int/drug-situation-and-policy-byhala-kerbage-psychiatrist-at-hotel-dieu-d/168075f2a9.

Kerr-Correa F, Igami TZ, Hiroce V, Tucci AM (2007) Patterns of alcohol use between genders: a cross-cultural evaluation. J Affect Disord 102:265-275

Kuehn BM (2007) Prescription drug abuse rises globally. JAMA 297: 1306

Lecrubier Y, Sheehan DV, Weiller E, Amorim P, Bonora I, Sheehan KH, Janavs J, Dunbar GC (1997) The Mini International Neuropsychiatric Interview (MINI). A short diagnostic structured interview: reliability and validity according to the CIDI European psychiatry 12:224-231

Locke GW, Shilkret R, Everett JE, Petry NM (2015) Interpersonal guilt and substance use in college students. Subst Abus 36:113-118

Lukács A, Simon N, Demeter JS, Kissné Dányi É, Kiss-Tóth E (2013) Alcohol consumption among university students. Egészségtudományi közlemények: a miskolci egyetem közleménye 3:57-61

Luthar SS, Latendresse SJ (2005) Children of the affluent: challenges to well-being. Curr Dir Psychol Sci 14:49-53

Mahfouz MS, Alsanosy RM, Gaffar AM, Makeen A (2014) Tobacco use among university students of Jazan Region: gender differences and associated factors. Biomed Res Int 2014:279231 
Maier LJ, Liechti ME, Herzig F, Schaub MP (2013) To dope or not to dope: neuroenhancement with prescription drugs and drugs of abuse among Swiss university students. PLoS One 8:e77967

Manubay JM, Muchow C, Sullivan MA (2011) Prescription drug abuse: epidemiology, regulatory issues, chronic pain management with narcotic analgesics. Prim Care 38:71-90

McHugh RK, Nielsen S, Weiss RD (2015) Prescription drug abuse: from epidemiology to public policy. J Subst Abus Treat 48:1-7

Mekonen T, Fekadu W, Chane T, Bitew S (2017a) Problematic alcohol use among university students. Front Psychiatry 8:86

Mekonen T, Fekadu W, Mekonnen TC, Workie SB (2017b) Substance use as a strong predictor of poor academic achievement among university students. Psychiatry J 2017:7517450

Mitchell MR, Potenza MN (2014) Addictions and personality traits: impulsivity and related constructs. Curr Behav Neurosci Rep 1:1-12

Mostardinha AR, Pereira A (2019) Fatores associados ao consumo de álcool e tabaco em estudantes universitários: Uma Revisão. Psychology, Community \& Health 8:85-98

Nasser AMA, Zhang X (2019) Knowledge and factors related to smoking among university students at Hodeidah University, Yemen. Tob Induc Dis 17:42

Osman T, Victor C, Abdulmoneim A, Mohammed H, Abdalla F, Ahmed A, Ali E, Mohammed W (2016) Epidemiology of substance use among university students in Sudan. J Addict 2016:2476164

Patrick ME, Wightman P, Schoeni RF, Schulenberg JE (2012) Socioeconomic status and substance use among young adults: a comparison across constructs and drugs. J Stud Alcohol Drugs 73: $772-782$

Peacock A, Leung J, Larney S, Colledge S, Hickman M, Rehm J, Giovino GA, West R, Hall W, Griffiths P, Ali R, Gowing L, Marsden J, Ferrari AJ, Grebely J, Farrell M, Degenhardt L (2018) Global statistics on alcohol, tobacco and illicit drug use: 2017 status report. Addiction 113:1905-1926

Ramis TR, Mielke GI, Habeyche EC, Oliz MM, Azevedo MR, Hallal PC (2012) Smoking and alcohol consumption among university students: prevalence and associated factors. Revista Brasileira de Epidemiologia 15:376-385

Redonnet B, Chollet A, Fombonne E, Bowes L, Melchior M (2012) Tobacco, alcohol, cannabis and other illegal drug use among young adults: the socioeconomic context. Drug Alcohol Depend 121:231239

Ruisoto P, Cacho R, Lopez-Goni JJ, Vaca S, Jimenez M (2016) Prevalence and profile of alcohol consumption among university students in Ecuador. Gac Sanit 30:370-374

Salameh P, Waked M, Aoun Z (2008) Waterpipe smoking: construction and validation of the Lebanon Waterpipe Dependence Scale (LWDS-11). Nicotine Tob Res 10:149-158
Salameh P, Khayat G, Waked M (2014) The Lebanese Cigarette Dependence (LCD) Score: a comprehensive tool for cigarette dependence assessment. Int J Behav Med 21:385-393

Schonnesson LN, Atkinson J, Williams ML, Bowen A, Ross MW, Timpson SC (2008) A cluster analysis of drug use and sexual HIV risks and their correlates in a sample of African-American crack cocaine smokers with HIV infection. Drug Alcohol Depend 97: 44-53

Smith DT, Mouzon DM, Elliott M (2018) Reviewing the assumptions about men's mental health: an exploration of the gender binary. Am J Mens Health 12:78-89

Substance Abuse and Mental Health Services Administration (2012): Results from the 2011 national survey on drug use and health: mental health findings, United States. Department of Health and Human Services; United States. Substance Abuse and Mental Health Services Administration. United States. Department of Health and Human Services; United States ...

Talih F, Daher M, Daou D, Ajaltouni J (2018) Examining burnout, depression, and attitudes regarding drug use among Lebanese medical students during the 4 years of medical school. Acad Psychiatry 42: 288-296

Tamim H, Terro A, Kassem H, Ghazi A, Khamis TA, Hay MM, Musharrafieh U (2003) Tobacco use by university students, Lebanon, 2001. Addiction 98:933-939

Tavolacci MP, Ladner J, Grigioni S, Richard L, Villet H, Dechelotte P (2013) Prevalence and association of perceived stress, substance use and behavioral addictions: a cross-sectional study among university students in France, 2009-2011. BMC Public Health 13:724

Webb E, Ashton C, Kelly P, Kamali F (1996) Alcohol and drug use in UK university students. Lancet 348:922-925

World Health Organization (1994): Lexicon of alcohol and drug terms published by the World Health Organization. Available from: https://www.who.int/substance_abuse/terminology/who_lexicon/ en/

World Health Organization (2001): AUDIT : the Alcohol Use Disorders Identification Test : guidelines for use in primary health care. Available from: https://www.who.int/publications/i/item/audit-thealcohol-use-disorders-identification-test-guidelines-for-use-inprimary-health-care

World Health Organization (2008): The global burden of disease, 2004 update. Available from: www.who.int

Young C, de Klerk V (2008)Patterns of alcohol use on a South African university campus: the findings of two annual drinking surveys. African Journal of Drug and Alcohol Studies 7

Publisher's note Springer Nature remains neutral with regard to jurisdictional claims in published maps and institutional affiliations. 